\title{
Torque Ripple Reduction in a DFIG-DC System by Resonant Current Controllers
}

\author{
Iacchetti M. F. ${ }^{1}$, Member IEEE, Marques G. D. ${ }^{2}$; Member IEEE, Perini R. ${ }^{1}$, Member IEEE
}

\begin{abstract}
A DFIG connected to a dc bus by a diode rectifier and a unique reduced-power PWM converter is considered in this paper. With respect to the traditional ac-grid connected DFIG, such a layout avoids the presence of the grid-side PWM converter and is an interesting solution to integrate the DFIG in a dc micro-grid together with other generating units, loads as well as storages. The peculiarity of the DFIG, which allows the control of the rotor current space vector independently of the mechanical position, offers two important benefits when the stator is connected to a constant voltage dc grid by a diode bridge: it avoids the need to boost the flux amplitude at low speed, and it allows to considerably reduce the torque ripple due to the diode commutation. This last issue is developed in the present paper by using a field oriented control scheme based on Proportional-Integral and Resonant Controllers. The proposed control is validated through simulation and experiments.
\end{abstract}

Index Terms - Doubly-fed induction machine, Resonant controllers, Dc-link, Rectifier, Field oriented control, Dc grid.

\section{NOMENCLATURE}

$\bar{i}_{s}, \bar{i}_{r}$ stator, rotor current space vector

$R_{S}, R_{r}$

$L_{s}, L_{k r}$

$p_{S}$

$t_{e}, t_{L}$

$\bar{v}_{s}, \bar{v}_{r}$

$V_{d c}$

$\gamma$

$\theta_{s}, \theta_{r}$

stator, rotor resistance

stator, $\Gamma$-model rotor inductance

instantaneous stator power

electromagnetic, load torque

stator, rotor voltage space vectors

dc-bus voltage

$\bar{\psi}_{S}, \bar{\psi}_{r}$

phase shift between $\bar{v}_{S}$ and $\bar{i}_{r}$

$d$-axis position with respect to the stator, rotor stator, rotor flux linkage space vector

$\omega_{b} \quad$ rated angular frequency

$\omega_{s}, \omega_{s r}, \omega_{m}$ stator frequency, slip speed, rotor speed (p.u.)

$\omega_{0}$ resonance frequency of the PI-R $\left(6 \omega_{b}\right)$

Superscripts

$\bar{x} \quad$ complex quantity

* $\quad$ set point value

(k)

$k^{\text {th }}$ harmonic component

Subscripts

$1,2,3$ phases

1: Dept. Of Energy - Politecnico di Milano- via La Masa 3420156 Milano (Italy)

2. Instituto Superior Tecnico, Universidade de Lisboa, 1049-001Lisbon, Portugal

\author{
$d, q \quad$ oriented frame axes \\ $s, r, R \quad$ stator, rotor, rotor in the $\Gamma$ equivalent circuit \\ $\alpha, \beta \quad$ stationary axes \\ $x \quad$ conjugate of $\bar{x}$
}

\section{INTRODUCTION}

DC distribution systems are being extensively studied because they exhibit several advantages as: no reactive power flow, copper savings, simple paralleling procedures [1]-[3]. Dc systems also allow an easy integration of several sources and storages on a single dc bus or on a dc grid bus by simplifying the layout and the number of electronic converters [4]. The promising benefits of dc distribution justifies the research toward cheap and effective interfaces between conventional ac generators and dc systems. For instance, the high performance control of squirrel cage induction generators or permanent magnet synchronous generators needs a threephase PWM rectifier rated to the full power of the system [5]. The use of a diode rectifier considerably reduces the costs but calls for an additional full power dc-dc conversion stage in order to allow some regulation in the system [6]-[7]. Even by using an additional dc-dc converter, the torque ripple due to the rectifier cannot be significantly mitigated.

As an alternative, the Doubly Fed Induction Generator connected to a diode rectifier on the stator and excited by a low power PWM converter through the rotor can be used, where both the diode bridge and the rotor converter are connected to the same dc grid: such a layout has been recently proposed in [8]-[9]. It should be noticed that the reduction of the cost of power electronics, which is the main reason for which DFIGs are widely used in ac wind energy conversion systems [10]-[12], is further pursued in this configuration, because one-less PWM converter is needed. Such a reasoning justifies the study of this DFIG-DC configuration, which reveals some peculiarities. First of all, even under an almost constant stator voltage (as in the connection to a constant voltage dc-bus by a diode bridge), the DFIG does not need to increase stator flux at low speed, because the stator frequency is kept near the rated value: this preserves a cheap sizing of the magnetic circuit. Moreover, the full freedom in the control of the rotor current space vector position and amplitude allows to implement a regulation of the instantaneous torque enabling to considerably reduce the torque ripple. It must be noticed that, for instance, none of these features exist in a field regulated synchronous generator connected to a diode bridge [13].

Recently, also the dual stator-winding induction generator (DWIG) has been considered for the connection to a dc bus by 
a diode rectifier [14]. This layout uses a single PWM converter as static excitation source: additional capacitors at the power winding side help to reduce the rating of the excitation converter. The system proposed in [14] exhibits great flexibility, because at low speed it can work similarly to a squirrel cage induction motor by delivering the power to the dc side through the PWM converter. However, a similar concept could be implemented also with traditional DFIGs in order to improve the power extraction capability [15].

A connection to a common dc grid with a voltage of few $\mathrm{kVs}$ is adequate for low power systems. For higher power systems, a dc-dc converter with a high-frequency insulating transformer can be used in order to boost the voltage to higher values [16].

Some control schemes specifically devoted to the DFIG connected to a diode bridge have been recently proposed. In [8], a Field Oriented Control (FOC) which regulates the average dc power by acting on a suitable fraction of the rotor flux linkage has been proposed, with the aim to tune the commutation inductance in such a way to minimize the derating of the DFIG due to the current harmonics. In [9], a FOC in the stator flux linkage frame has been suggested. The peculiarity of the scheme in [9] is the use of the $d$-axis to control the stator frequency and of the $q$-axis to control the torque. The choice of the $d$-axis current as control variable for the frequency is due to the behavior of the rectifier connected to a constant voltage dc link [17], which reflects to the ac side an almost constant amplitude voltage, calling for an almost constant product flux-frequency. By contrast, in stand-alone ac DFIGs the $q$-axis rotor current is used to fix the orientation of the control frame and then to indirectly regulate the frequency, whereas the $d$-axis rotor current is devoted to the voltage regulation [18]-[20].

However, the diode rectifier connected to a constant voltage dc-bus applies a strongly distorted voltage on the stator winding and injects current harmonics. As described in [21][22], the interaction between the resulting stator flux linkage and current harmonics produces a considerable torque ripple whose fundamental frequency is six times the stator frequency. The main consequence of the torque ripple is the fatigue strength and wear of mechanical components.

In order to reduce the torque ripple, a shunt filter can be connected to the DFIG stator [23], so that a sinusoidal operation of the DFIG can be obtained. However, such a solution needs an additional three-phase PWM converter and suitable decoupling inductances which increase the cost and the bulk of the power electronics. In ac DFIGs feeding non linear loads, the grid-side converter can be controlled as active filter [18]. Nevertheless, these solutions are justified when also the ac voltage quality has to be guaranteed: however, this is not a requirement in the considered DFIG-DC system.

If a FOC technique is implemented for the DFIG, the torque ripple could be reduced by acting only on the rotor side converter, by synthesizing suitable reference rotor current signals and by increasing the capability of the rotor current loops in tracking the $6^{\text {th }}$ harmonic [22]. However, PI controllers implemented in the stator flux frame are ineffective to this purpose, because they should be designed with an unrealistic bandwidth. It should also be noticed that, in DFIG systems, a high bandwidth of the current loops reduces the damping of the stator flux linkage. Recently, new current control schemes have been applied to ac DFIG systems with the aim to selectively control specified harmonics: Resonant Controllers (RC) [25], multiple PI controllers implemented in the harmonic frames [22],[24],[26], vector PI controllers .

In [28], a refinement of the FOC scheme in [9] has been proposed: resonant controllers are used with the aim to improve the rotor current tracking, in such a way to kill the main component of the torque ripple. However, [28] reports only preliminary simulation results and does not include any discussion about the tuning of the current controllers.

This paper provides the theoretical framework for the scheme proposed in [28] and includes a systematic experimental validation. Other recent works dealing with the DFIG control enhancement by RCs [25]-[26] are based on the classical FOC, namely: the d-axis rotor current is used either for the reactive power regulation or for the voltage regulation in stand-alone systems. Moreover only the operation with a weakly distorted voltage or with a sinusoidal voltage and distorted currents (in stand alone systems) was considered. As novelty and differently from the schemes in [25]-[26], resonant controllers are here adopted by preserving the peculiarity of [9], namely: the use of $d$-axis rotor current for the frequency regulation and the $q$-axis rotor current for the torque control. The minimization of the torque ripple here is pursued even operating with a strongly distorted stator voltage and flux, due to the diode bridge, which represents the entire DFIG load. With respect to [9], a flux estimator with a natural decay term is used, as well as an easier direct estimation of the frequency instead of a closed-loop frequency detector. Section II summarizes the system layout and the related model equations. Section III explains the mechanism which produces the torque ripple in the considered layout. Section IV describes the control scheme including the frequency estimation, the field orientation and the current control. The current control based on PI-R controllers is described in Section $\mathrm{V}$ where the background for the controller design is also provided. Simulative and experimental results are included in Section VI and VII respectively: they prove the effectiveness of the control in suppressing the main torque ripple component.

\section{System LAYOUT AND MODELING}

Fig. 1 describes the system considered in this paper: a DC link is simultaneously connected to the diode rectifier placed on the stator and to the rotor PWM converter. Differently from the ac-grid connected DFIG, the grid side converter is avoided.

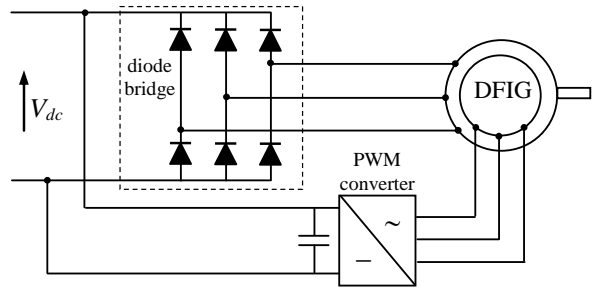

Fig. 1. Considered system: the DFIG is connected to a DC link through a diode rectifier. The same dc link feeds the rotor PWM converter. 
According to the $\Gamma$ equivalent circuit in Fig. 2 in a generic frame $d q$, the DFIG is represented by the following equations in p.u. (positive torque $t_{e}$ in the operation as generator)

$$
\begin{aligned}
& \bar{v}_{s}=-R_{s} \bar{i}_{s}+\frac{1}{\omega_{b}} \frac{d \bar{\psi}_{s}}{d t}+j \frac{1}{\omega_{b}} \frac{d \theta_{s}}{d t} \bar{\psi}_{s}, \\
& \bar{v}_{R}=R_{R} \bar{i}_{R}+\frac{1}{\omega_{b}} \frac{d \bar{\psi}_{R}}{d t}+j \frac{1}{\omega_{b}} \frac{d \theta_{r}}{d t} \bar{\psi}_{R}, \\
& \bar{\psi}_{s}=L_{s}\left(-\bar{i}_{s}+\bar{i}_{r}\right) \quad, \quad \bar{\psi}_{R}=\bar{\psi}_{s}+L_{k r} \bar{i}_{R}, \\
& t_{e}=-\operatorname{Im}\left(\bar{\psi}_{S} \underline{i}_{-r}\right), \quad p_{s}=\operatorname{Re}\left(\bar{v}_{S} \underline{i}_{S}\right) .
\end{aligned}
$$

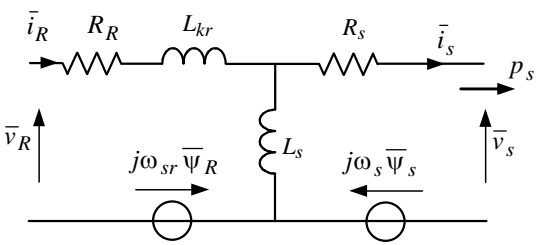

Fig. 2. $\Gamma$ equivalent circuit of the DFIG.

\section{GENESIS OF THE TORQUE RIPPLE}

When the stator is connected to a constant voltage source through a diode bridge, the stator voltage is intrinsically strongly distorted. For instance, if the rectifier operates in mode $3 / 3$ [17] the stator voltage is clamped to the three-step square wave shown in Fig. 3.

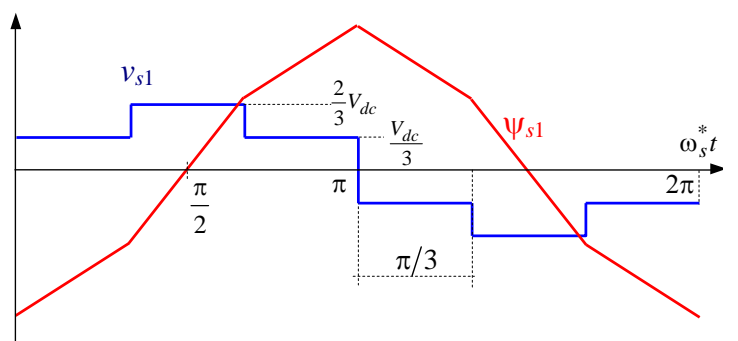

Fig. 3. Stator voltage and flux waveforms when the diode bridge operates in mode $3 / 3$.

Even in mode 2/3, such a square wave can provide a good approximation and considerably simplifies the study of the operation. In particular, by neglecting the stator resistance, it turns out that the stator flux waveform is well approximated by the linear piecewise curve in Fig. 3 corresponding to the exact flux waveform in mode $3 / 3$. The flux harmonics, in the stator reference $s \alpha \beta$ and by considering the operation at the p.u. reference $\omega_{s}{ }^{*}$ frequency, are given by

$$
\bar{\psi}_{s, \alpha \beta \beta}^{(k)}=-\frac{2}{\pi} \frac{V_{d c}}{\omega_{s}^{*}} \frac{1}{k|k|} e^{j k \omega_{s}^{*} \omega_{b} t}, k=1,-5,7,-11,13, \ldots \ldots
$$

Since also the stator currents are distorted, if no particular control solutions are adopted, the interaction between the flux and current harmonics causes a noticeable torque ripple. By considering only the $5^{\text {th }}$ and $7^{\text {th }}$ harmonics in the stator voltage and currents, and by using (5) it can be proven [21],[25] that the most significant component of the torque ripple is the $6^{\text {th }}$ harmonic $t_{e}^{(6)}$ given by

$$
\begin{array}{r}
t_{e}^{(6)} \cong \frac{2 V_{d c}}{\pi \omega_{s}^{*}} \operatorname{Im}\left(\left(\underline{i}_{s}^{(5)}+\frac{\underline{i}_{s}^{(1)}}{49}\right) e^{j 6 \omega_{s}^{*} \omega_{b} t}+\right. \\
\left.+\left(\underline{i}_{s}^{(7)}-\frac{\underline{i}_{s}^{(1)}}{25}\right) e^{-j 6 \omega_{s}^{*} \omega_{b} t}\right)
\end{array}
$$

\section{REgUlation SCHEME}

\section{A. General principle}

If the dc voltage $V_{d c}$ is supposed to be regulated by external apparatus connected to the same dc grid, the considered system shares some analogies with both the ac-grid connected and ac stand-alone DFIG. On one hand, the presence of the dc-grid allows to regulate the DFIG in order to deliver all the available power [29]: to this purpose, the control requires a reference torque command. On the other hand, the dc-grid does not imposes any stator frequency to the DFIG, so that some frequency control should be implemented, similarly to stand alone ac DFIGs. Nevertheless, the system in Fig. 1 does not feed any ordinary ac load, so that it is enough that the frequency belongs to a range near the rated value, and there are no special requirements about the quality of the stator voltage. The reference frequency $\omega_{s}{ }^{*}$ could also be varied according to the operating conditions, in such a way to optimize the performance of the system: such an opportunity is not investigated in this paper, and the reference frequency is set to the rated value $\omega_{s}{ }^{*}=1$ p.u.. The FOC described in [9] is considered in this paper, with some improvements related to the simplification of the frequency and flux estimator and to the analysis and compensation for the torque ripple. The relevant reference frames are shown in Fig. 4, whereas the control scheme is shown in Fig. 5.

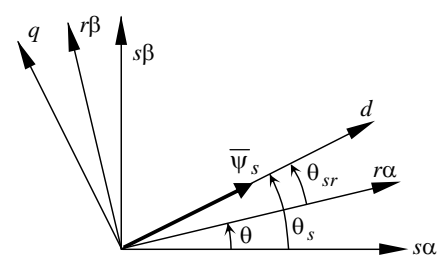

Fig. 4. Reference frames for the FOC

Even if a diode rectifier feeding a constant voltage dc link exhibits very different operation modes [17], the ac first harmonic $V_{s 1 p k}$ voltage measured immediately behind the diode rectifier varies in a very narrow range, precisely:

$$
\frac{1}{\sqrt{3}} V_{d c} \leq V_{s 1 p k} \leq \frac{2}{\pi} V_{d c} \Rightarrow 0.58 \leq \frac{V_{s 1 p k}}{V_{d c}} \leq 0.63 .
$$

If $V_{s 1 p k}$ is below the left boundary value in (7), the diode bridge is not conducting at all, whereas the right boundary concerns the operation in mode $3 / 3$ or Continuous Conduction Mode (CCM), where the ac voltage is clamped to the square wave. 
Equation (7) together with the assumption of a negligible stator resistance justifies the basic hypothesis adopted in [9], namely: the DFIG in Fig. 1 operates with an almost constant stator EMF amplitude, then also with an almost constant product frequency-flux. Thus, in order to control the frequency, one can control the stator flux amplitude, by working in the stator flux oriented frame and by adjusting the $d$-axis rotor current. Simultaneously, the $q$-axis reference current is devoted to the torque regulation.

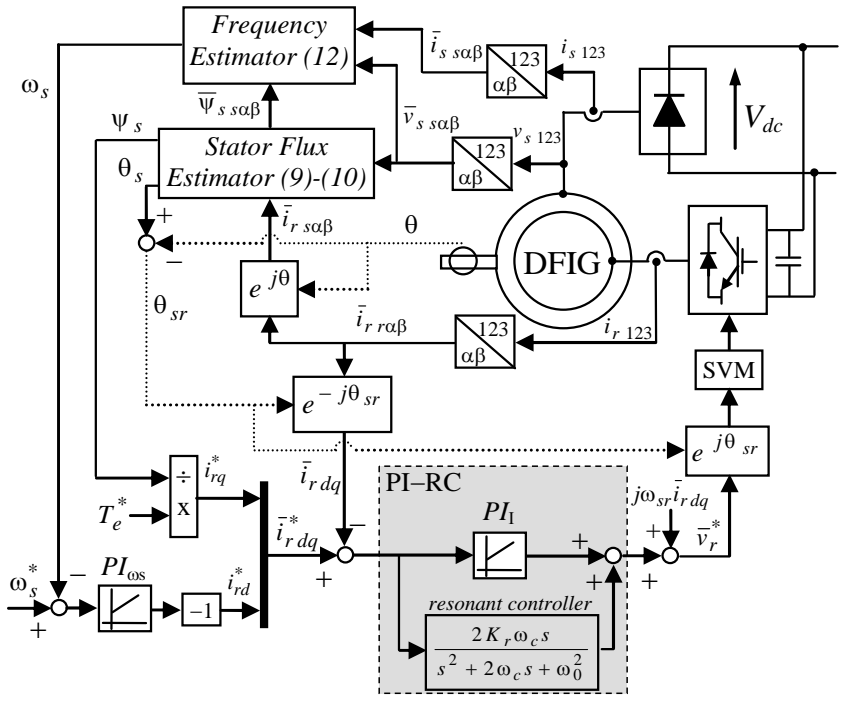

Fig. 5. FOC scheme for the torque and frequency regulation

When the diode bridge is conducting, the field orientation along the stator flux linkage is simply obtained by using the slip angle $\theta_{s r}$ in the frame transformations:

$$
\theta_{s r}=\theta_{s}-\theta
$$

where the stator flux angle $\theta_{s}$ is calculated by using the following stator flux estimator [31]

$$
\begin{aligned}
\frac{1}{\omega_{b}} \frac{d \bar{\psi}_{s s \alpha \beta}}{d t} & =\bar{v}_{s s \alpha \beta}+R_{s} i_{R r \alpha \beta} e^{j \theta}-\frac{R_{s}}{L_{s}} \bar{\psi}_{s s \alpha \beta} \\
\theta_{s} & =\arctan \left(\psi_{s s \beta} / \psi_{s s \alpha}\right) .
\end{aligned}
$$

The formulation (9) is obtained by using (3) in order to eliminate the stator current in the stator EMF. As an advantage, with respect to the flux estimator used in [9] and based on the direct integration of the stator EMF with a bandpass or low-pass filter, (9) already contains the natural decay term $-\left(R_{s} / L_{s}\right) \bar{\psi}_{s s \alpha \beta}$ which suppresses the drift in the integration and damps the oscillations due to an imperfect matching of the initial condition for the flux components.

As an alternative to the measure of the mechanical position in (8), either rotor position or also slip angle observers could be implemented [18]-[19], [20], [29]-[32].

During the no load operation (with zero torque reference) the aforementioned control strategy fails, because the stator flux angle is not observable and the relation $\omega_{s} \psi_{s} \approx$ const. is no longer satisfied. However, as pointed out in [9], in such a condition it is enough to switch the regulation to a "no load operation control", where the reference angle for the FOC is obtained by integrating the reference frequency and where the $d$-axis is regulated in such a way to operate near the boundary of the incipient conduction of the diode bridge. The details of the no load control have been discussed in [9] and are not repeated here, also because at no load the DFIG operates with sinusoidal voltage waveforms and zero electromagnetic torque.

\section{B. Frequency control}

As shown in [9], the frequency can be regulated by processing the error frequency through a PI controller which calculates the required $d$-axis reference rotor current needed to have the appropriate flux level related to the dc voltage. The reference $d$-axis rotor current is then given by

$$
i_{r d}^{*}=-\left(k_{p \omega}+\frac{k_{i \omega}}{s}\right)\left(\omega_{s}^{*}-\omega_{s}\right) .
$$

The negative sign before the second member of (11) and after the $\mathrm{PI}_{\omega \mathrm{\omega}}$ in Fig. 5 can be justified by observing that, being the product flux-frequency almost constant, an increase of the stator flux (namely of $i_{r d}$ ) causes a decrease of the frequency. This is well depicted in the simplified first-harmonic small signal-model of the frequency loop in Fig. 6, which is deduced by linearizing the imaginary part of (1) in the field oriented frame [9] around a steady state point (with $\psi_{s 0}$ and $\omega_{s 0}$ ). To this purpose, it should be noticed that the diode rectifier imposes an ac voltage whose first harmonic is almost in phase with the first harmonic of the stator current, resulting in an almost zero average $d$-axis stator current, as experimentally assessed in [9].

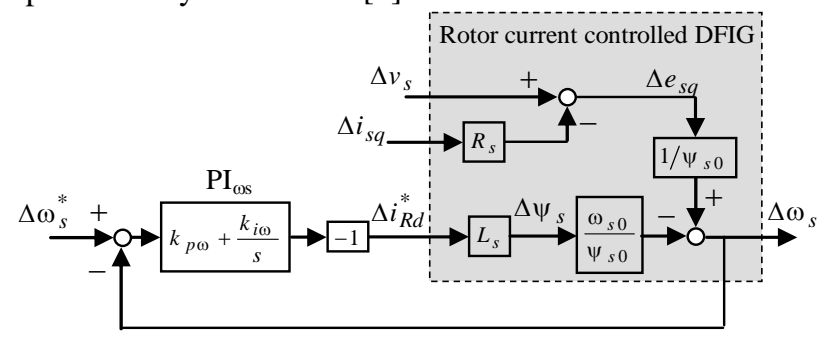

Fig. 6. Simplified frequency loop with a rotor current controlled DFIG-DC

As far as the frequency estimation is concerned, differently from [9], where a frequency detector based on an integral controller was employed, here the symbolic derivative of (10) in p.u. is used [33], so that

$$
\omega_{s}=\frac{1}{\omega_{b}} \frac{d \theta_{s}}{d t}=\frac{e_{s s \beta} \psi_{s s \alpha}-e_{s s \alpha} \psi_{s s \beta}}{\psi_{s s \alpha}^{2}+\psi_{s s \beta}^{2}},
$$

which avoids any additional closed loop detector.

Due to the distortion of the voltage and flux waveforms, at steady state, $\omega_{s}$ is affected by considerable ripple. However, the purpose of the control is the regulation of the average frequency, then the crossover frequency of the frequency 
controller $\mathrm{PI}_{\omega}$ has to be relatively low.

\section{Torque control with PI-R current controllers}

In order to implement a torque control, the reference $q$-axis current is calculated by dividing the reference torque $T_{e}{ }^{*}$ signal by the stator flux amplitude $\psi_{s}$

$$
i_{r q}^{*}=T_{e}^{*} / \psi_{s} .
$$

Since, due to the diode commutation, the stator flux linkage amplitude is oscillating around its average value at six times the average stator frequency, the $q$-axis reference current contains a significant ripple at $6 \omega_{b}$ which should be correctly tracked in order to annihilate the corresponding ripple component in the electromagnetic torque.

It is well known that PI regulators are not fully adequate to track harmonic reference signals. In this paper, additional resonant controllers [25] tuned at $\omega_{0}=6 \omega_{b}$ in parallel with the PI controllers are used in current loops. PI-RCs allow to considerably improve the current tracking by also preserving a high rejection capability to the disturbances, as it will be shown in Section V. Moreover, by using RCs, the global bandwidth of the current loops remains moderate, that avoids a reduction of the stator flux linkage damping [35].

Then, the current controllers are represented by the following complex relation

$$
\bar{v}_{r}^{*}=\left(k_{p \omega}+\frac{\omega_{b} k_{i \omega}}{s}+\frac{2 k_{r} \omega_{c} s}{s^{2}+2 \omega_{c} s+\omega_{0}^{2}}\right)\left(\bar{i}_{r}^{*}-\bar{i}_{r}\right) .
$$

\section{DESIGN OF THE PI-RESONANT CURRENT CONTROLlERS}

Fig. 7 shows the current loops, which include the PI-RC, the converter and the rotor circuit, represented by the leakage inductance and the resistance. Since the cross-coupling terms $j \omega_{s r} L_{k r} \bar{i}_{r d q}$ are compensated by feed-forward signals (see Fig. 5), the residual uncompensated rotor back EMF $\bar{d}$ is given by

$$
\bar{d}=\bar{v}_{s d q}-j \omega_{m} \psi_{s}-\frac{R_{s}}{L_{s}} \psi_{s} .
$$

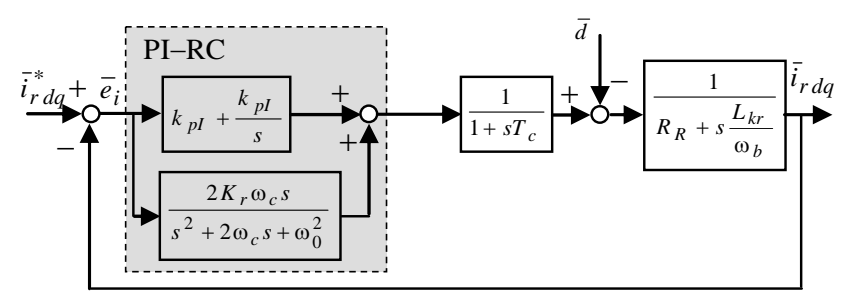

Fig. 7. Current loops

The open loop transfer function is

$$
\frac{\bar{i}_{r d q}}{\bar{i}_{r d q}^{*}}=G_{I}(s)=C_{I}(s) \frac{1}{1+s T_{c}} \frac{1}{R_{R}+s L_{k r} / \omega_{b}}
$$

where $C_{I}(s)$ is the transfer function (17) of the whole PI-RC

$$
\begin{aligned}
C_{I}(s)=\frac{1}{s\left(s^{2}+2 \omega_{c} s+\omega_{0}^{2}\right)}( & k s_{p} s^{3}+\left(k_{i I}+2 \omega_{c}\left(k_{p I}+K_{r}\right)\right) s^{2}+ \\
& \left.+\left(2 \omega_{c} k_{i I}+\omega_{0}^{2} k_{p I}\right) s+\omega_{0}^{2} k_{i I}\right)
\end{aligned}
$$

Recently, the theory of Naslin's Polynomials with tunable damping [34] has been used to provide a framework for the design of PI-RCs [26]: however, the results of the Naslin theory rigorously hold only for loop transfer functions with a unit numerator. Moreover, the procedure calls for the solution of a non-linear equation with multiple solutions, in order to find the so called Naslin frequency, which is involved in all the expressions of the controller parameters. Besides, the analytical treatment becomes very cumbersome if the transfer function of the converter (time constant $T_{c}$ ) has to be included in the analysis.

As an alternative, traditional design of the PI controller can be adopted by assigning a reasonable value for the cross-over frequency $\omega_{c I}$, which is not significantly affected by the resonant controller. A classical method consists in cancelling the dominant pole in (16) due to the rotor circuit time constant by using the zero of the PI. The cancellation, as well as the constraint on the approximated value of the cross-over frequency $\omega_{c I}$ (with only the PI), provides the values of $k_{p I}$ and $k_{i I}$. Then, the RC parameters can be tuned in order to guarantee appropriate selectivity and phase margin. The bandwidth $\omega_{c}$ and the gain $K_{r}$ of the RC strongly affect the phase margin of the complete open loop transfer function through the product $K_{r} \cdot \omega_{c}$ [25]. The bandwidth defines the selectivity (sharpness) of the RC and should belong to the range 5 - $20 \mathrm{rad} / \mathrm{s}$ [22].

Fig. 8 shows the bode diagram of the closed loop current transfer function which has been achieved by setting $\omega_{c I}=$ $2 \pi \cdot 300 \mathrm{rad} / \mathrm{s}$ (with only the PI controller), $\omega_{c}=7\left(\mathrm{rad} / \mathrm{s}\right.$ ) and $K_{r}$ $=30$ p.u.. This value of $K_{r}$ is set in order to have a phase shift less than 3 deg in the closed loop transfer function.

The resulting cross-over frequency of the current loop and the phase margin calculated by (16) are $344 \mathrm{~Hz}$ and $51.3 \mathrm{deg}$ respectively, whereas the gain and the phase of the closed loop transfer function at $\omega=\omega_{0}$ are 1.006 p.u. and 2.86 deg respectively, which confirm the good tracking capability for the harmonic reference signals at the resonance frequency.

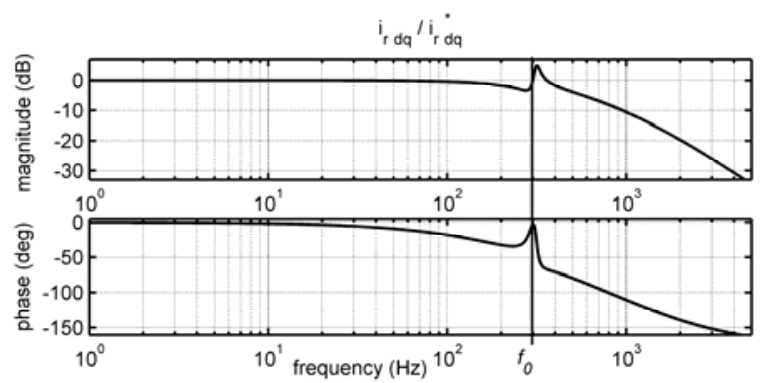

Fig. 8. Bode diagram of the closed loop current transfer function.

Thanks to the high gain of the open loop transfer function at $\omega=\omega_{0}$, the rejection to the residual disturbance $\bar{d}(15)$ (whose main component is at $\left.\omega=\omega_{0}\right)$ is quite high $(\approx-30 \mathrm{~dB})$, as 
shown in Fig. 9, so that no feed-forward compensation of $\bar{d}$ is required.

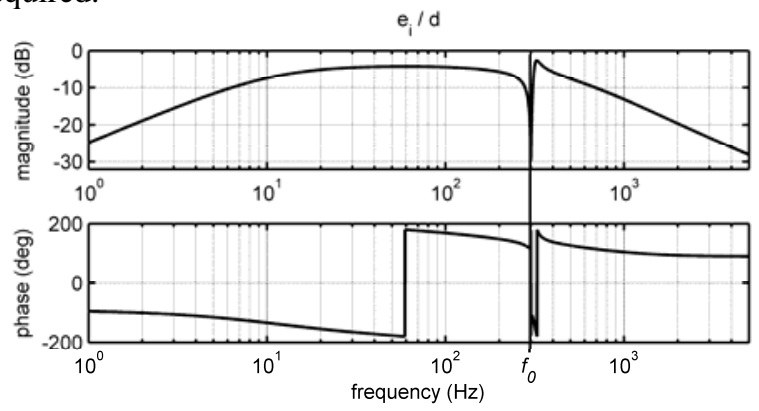

Fig. 9. Bode diagram of the disturbance rejection transfer function.

\section{Simulation Results}

The simulations have been performed by using MatlabSimulink and by considering a $3.7 \mathrm{~kW}$ slip-ring machine which is used also in the experimental tests: the parameters are in the Appendix. Actually, the used machine was designed for motoring applications, then the rated rotor magnetomotive force is lower than the stator one. As explained in [8], when the DFIG is connected to a diode bridge, the whole magnetizing current has to be supplied through the rotor and then the rotor should have the highest rated MMF. Due to this reason, in order to have some margin for the torque current component in the tests, the connections of the stator and rotor have been inverted. The same device has been adopted in the simulation model. Nevertheless, to have coherence with the theory, also the names of the two structures have been exchanged (see Fig. 14), i.e. the "stator" depicts now the rotating part (with the lowest rated MMF, connected to the diode bridge), whereas the "rotor" depicts the fixed part (with the highest rated MMF).

The control routine has been written in $C$-code and embedded in a block triggered at any sampling-switching time $(100 \mu \mathrm{s} \Rightarrow 10 \mathrm{kHz})$. Unit sample delays have been placed at the output of the control routine, in order to model the sampling delay. The PI-R controllers have been tuned as described in Section IV, the cross-over frequencies of the frequency controller has been set at $2 \mathrm{~Hz}$. The common dc bus is fed with a constant voltage source $(220 \mathrm{~V})$.

Simulations have been performed by considering an ideal speed regulated prime mover, which operates at constant speed, so that the correctness of the frequency tracking can be indirectly obtained by analyzing the period of the rotor currents. Further (experimental) investigations with variable speed are performed in Section VII.

Fig. 10 shows the performance of the basic control system during a step in the reference torque from 0.1 p.u. to 0.5 p.u. and vice-versa, when the resonant current controllers are disabled. The rotor current components (reference and actual), the stator flux linkage, the stator frequency, the mechanical speed and the instantaneous torque are reported. The estimated frequency is affected by a high ripple due to the distortion in the stator flux linkage. Nevertheless, as required, the system is able to restore the average frequency at its set point. However a noticeable torque ripple component at 300 $\mathrm{Hz}$ is produced: its amplitude is about 0.15 p.u.. This is well depicted in Fig. 11, which reports the steady state stator voltage and current as well as the instantaneous torque and the instantaneous stator power, when $T_{e}=0.5$ p.u.. It is interesting to notice that, differently from the torque $t_{e}$, the stator power $p_{s}$ has a low ripple whose main frequency is $12 \omega_{b}(600 \mathrm{~Hz})$.
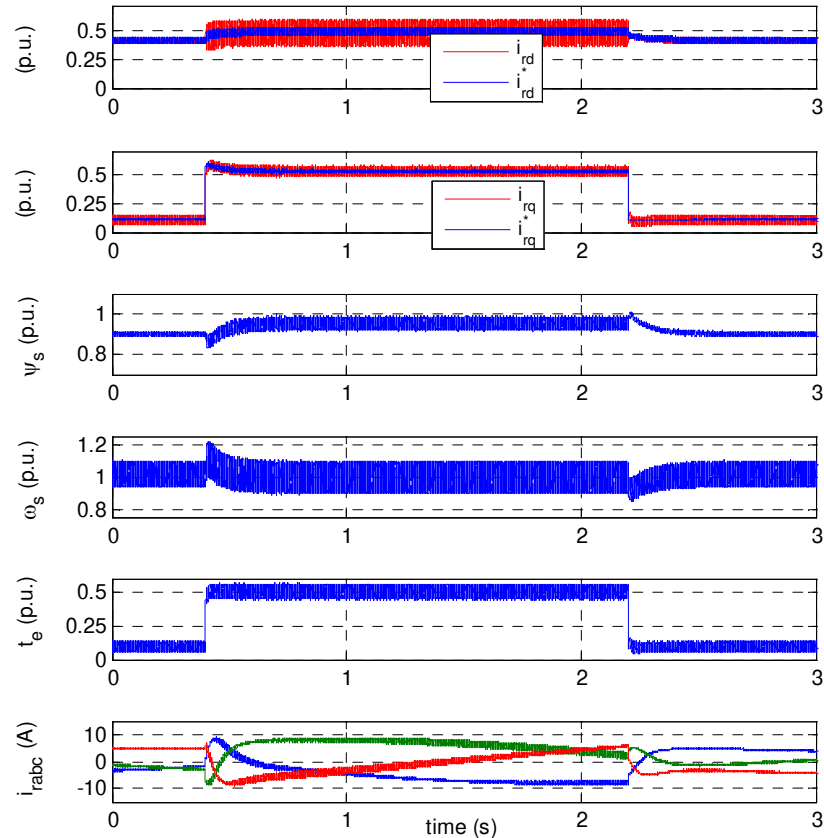

Fig. 10. Basic control (resonant controllers disabled): response to a step in the reference torque (simulations).

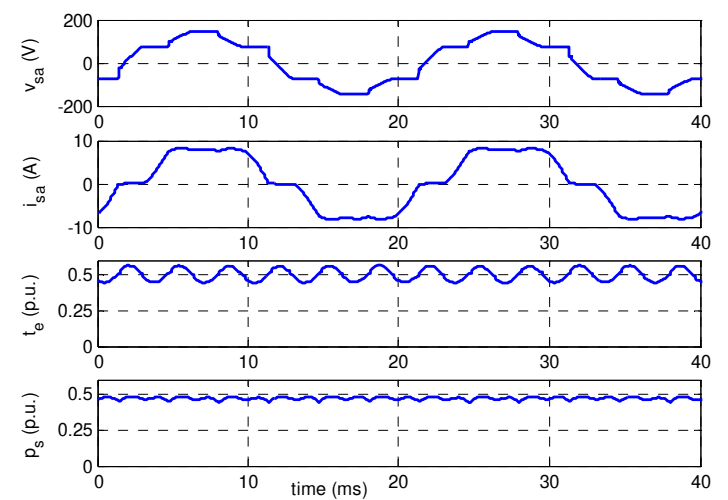

Fig. 11. Steady state stator currents, voltages, and electromagnetic torque in the operation with resonant controllers disabled ( $T_{e}=0.5$ p.u.). (Simulations)

Fig. 12 reports the same transient response as in Fig. 10 when the resonant controllers are enabled. The system behaves similarly to the previous case (Fig. 10), but the ripple in the torque is drastically reduced. This is clearly shown in Fig. 13, where the steady state waveforms are reported: only a ripple component at $12 \omega_{b}(600 \mathrm{~Hz})$ survives. It can also be noticed that the ripple in the stator power is increased and a noticeable component at $6 \omega_{b}(300 \mathrm{~Hz})$ appears. Achieving either reduced torque ripple or reduced stator power ripple involves different control targets [22]: they cannot be simultaneously obtained by acting only on the rotor side converter. Only the sinusoidal operation would guarantee both constant torque and stator power, but this is precluded due to the distorted voltage reflected at the ac side by the diode bridge. 
As for the stator frequency, the signals in Figs. 10 and 12 exhibit a similar ripple: the average frequency is correctly tracked, as indirectly shown by the period of the rotor currents (notice that the rotor is at synchronism).
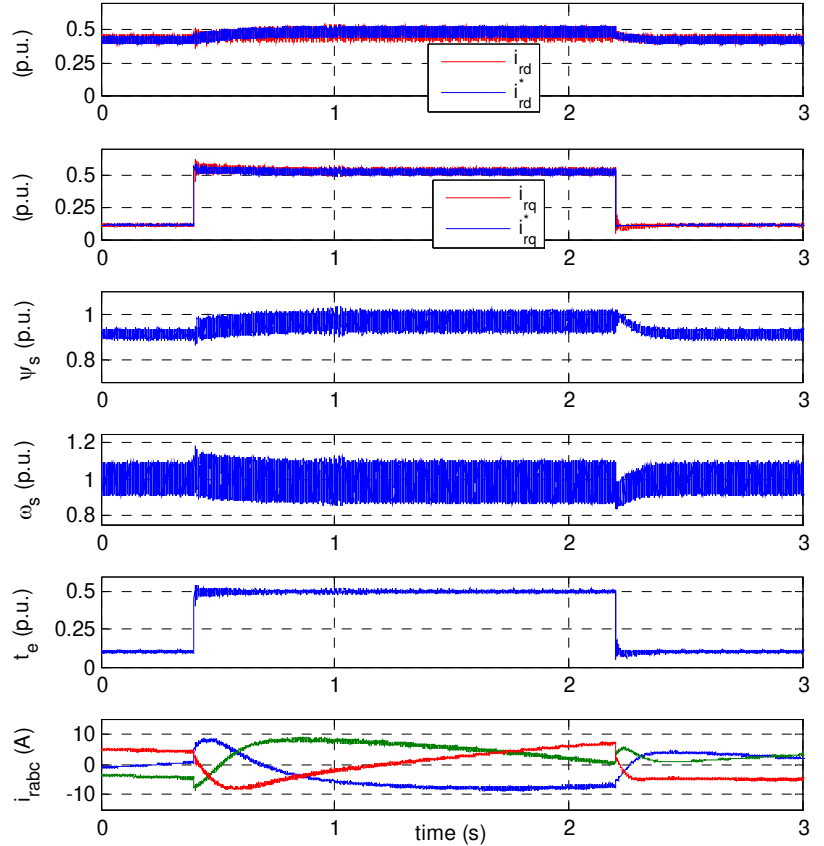

Fig. 12. Resonant controllers enabled: response to a step in the reference torque (simulations).
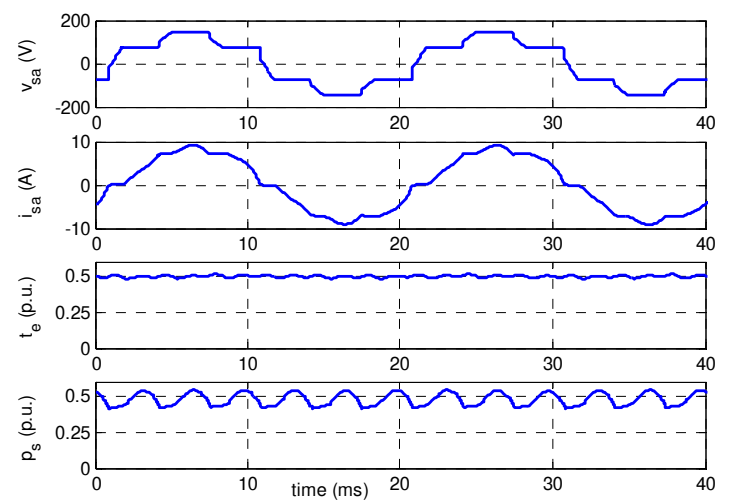

Fig. 13. Steady state stator current, voltage, electromagnetic torque and stator power in the operation with resonant controllers enabled ( $T_{e}=0.5$ p.u.). (Simulations)

\section{EXPERIMENTAL RESULTS}

Fig. 14 illustrates the setup used in the experimental tests.

As mentioned in Section $\mathrm{V}$, the stator and the rotor connections have been exchanged, so that the inverter acts on the stator winding, which in the used machine has the highest rated MMF. A separated excitation DC machine rated to 30 $\mathrm{kW}$ and driven by an Induction Machine (SCIM) creates the dc net (at $220 \mathrm{~V}$ ) which is connected to both the rotor PWM converter and the stator diode bridge. A DSpace platform (DS 1103) has been used to implement the control algorithm: the switching and sampling frequency is $10 \mathrm{kHz}$.

Figs. 15-16 shows the response of the basic control system (without resonant controllers) during some step variations of the reference torque.

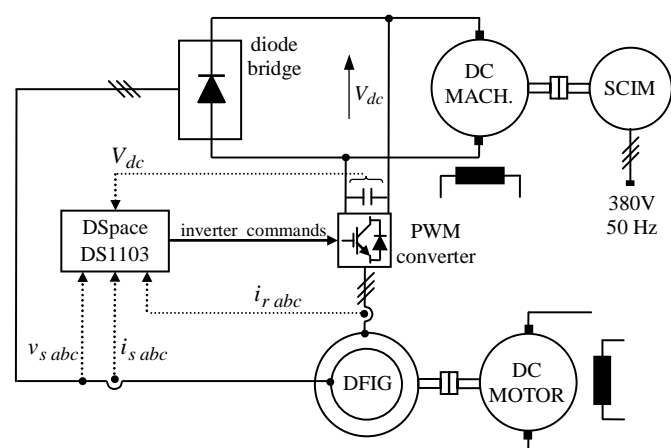

Fig. 14. Experimental setup.
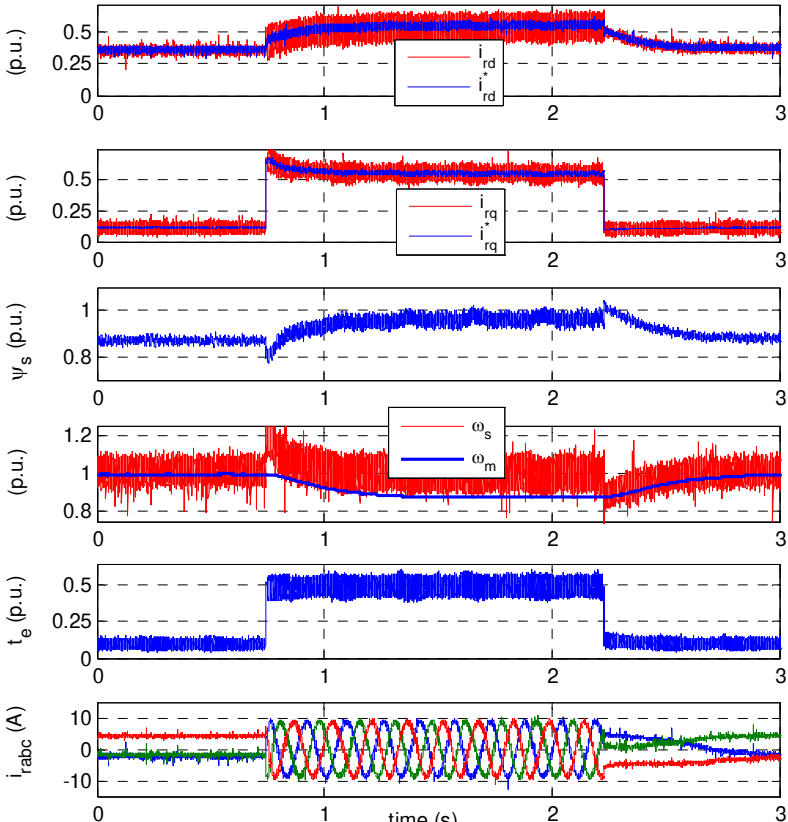

Fig. 15. Experimental behavior of the basic system (resonant controllers disabled) at synchronism during some steps in the moving torque.

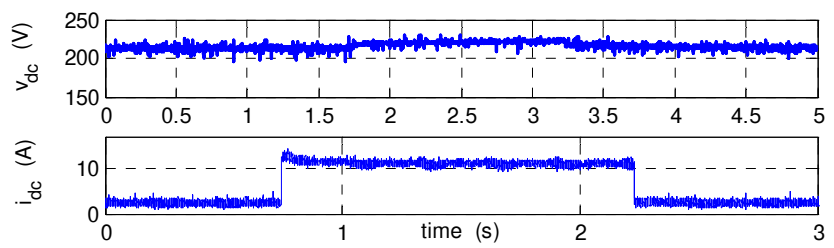

Fig. 16. Dc voltage and current in the test of Fig. 15 (RC disabled)

As verified by simulations, the dynamic of the torque control is adequate, but the torque is affected by a considerable ripple. As in the simulations, also the frequency contains a significant ripple due to the distortion of the stator flux linkage, but the average value is regulated according to the dynamics of the frequency controller. The speed is not controlled in this test, so that it varies in such a way to make the DC motor able to deliver the requested torque, according to its steady state torque characteristic.

The dc voltage and current at the dc side of the diode bridge are shown in Fig. 16: the dc voltage slightly increases due to the negative voltage drop across the dc cable and the armature resistance of the dc generator. 
Fig. 17 shows the waveforms of the stator voltage and current as well as torque and instantaneous stator power.

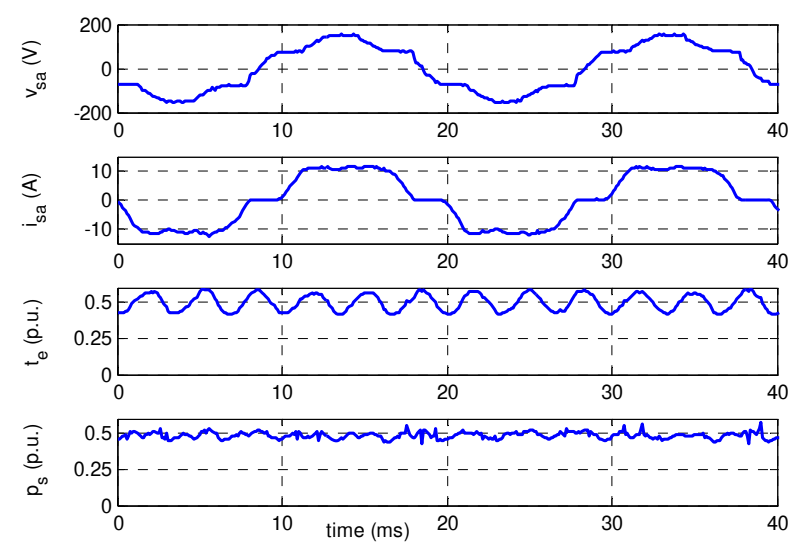

Fig. 17. Experimental steady state waveforms of the basic control scheme at synchronism with $T_{e}=0.5$ p.u. (resonant controllers disabled).

The torque ripple is about 0.2 p.u.: as expected, its main component is at $300 \mathrm{~Hz}$. The diode rectifier operates in mode $2 / 3$ [17]: the stator voltage is strongly distorted, because in the subintervals where three diodes are conducting it is clamped to a three-step square wave. The instantaneous stator power exhibits a lower ripple ( 0.04 p.u. mainly at $\left.12 \omega_{b}, 600 \mathrm{~Hz}\right)$ with respect to the torque (ripple 0.2 p.u. at $6 \omega_{b}, 300 \mathrm{~Hz}$ ).

The response to a step in the reference torque has been also tested by enabling the resonant controllers. The results during the torque transients are shown in Fig. 18 and 19.
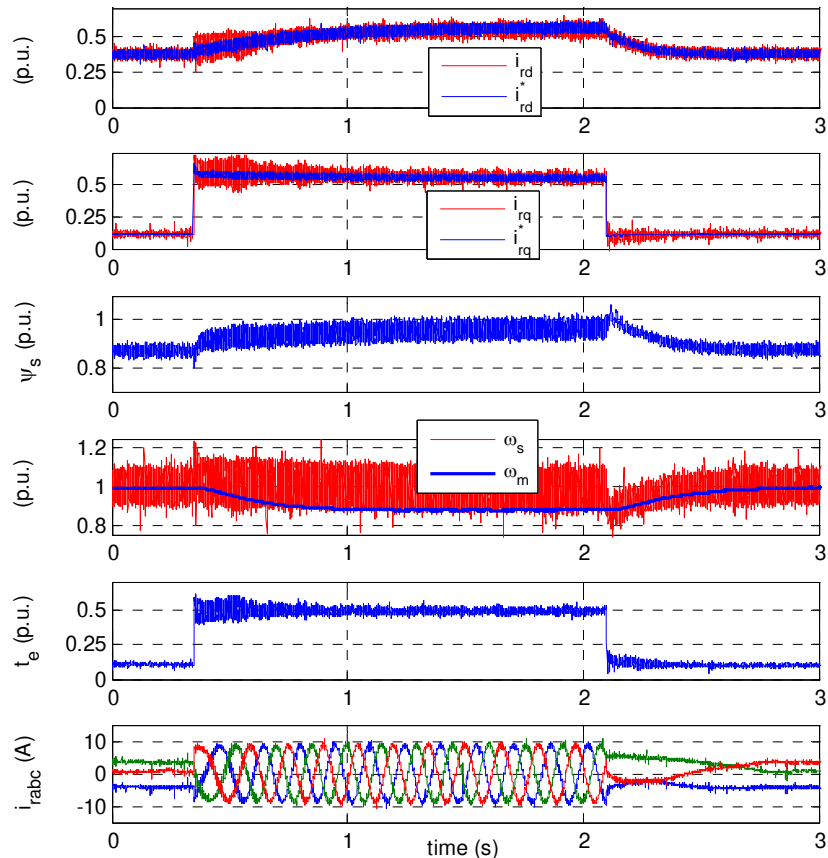

Fig. 18. Experimental behavior of the enhanced control system (resonant controllers enabled) at synchronism during some steps in the moving torque.

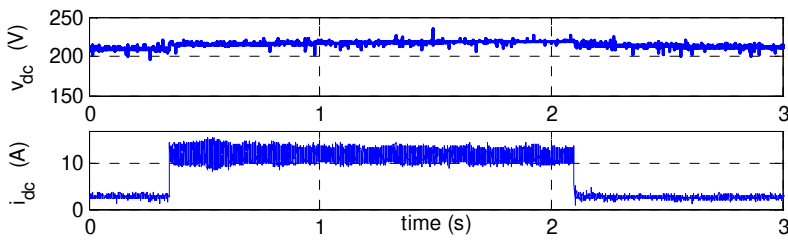

Fig. 19. Dc voltage and current in the test of Fig. 17 (RC enabled).

As far as the dynamics of the torque and frequency control are concerned, the enhanced control system performs similarly to the basic system. The major difference concerns the torque ripple, which is considerably reduced with respect to the operation with the basic control. By contrast, the ripple in the dc current shown in Fig. 19 is higher than the one in the operation with RC disabled (see Fig. 16). In fact, being the dc voltage quite stable and the dc power mainly due to the stator power, the ripple in the dc current is closely related to the stator power ripple, which increases when RCs are enabled. Differently from the torque ripple, the dc current ripple is not a great concern, because it can be easily filtered.

Fig. 20 reports the steady state waveforms of the stator voltage and current as well as the torque and stator power when $T_{e}^{*}=0.5$ p.u.. In particular, the harmonic component at $6 \omega_{b}(300 \mathrm{~Hz})$ in the torque is practically eliminated, thanks to the resonant controllers. Conversely, as previously assessed by simulations, a noticeable ripple at $6 \omega_{b}(300 \mathrm{~Hz})$ in the instantaneous stator power appears when the resonant controllers are enabled.
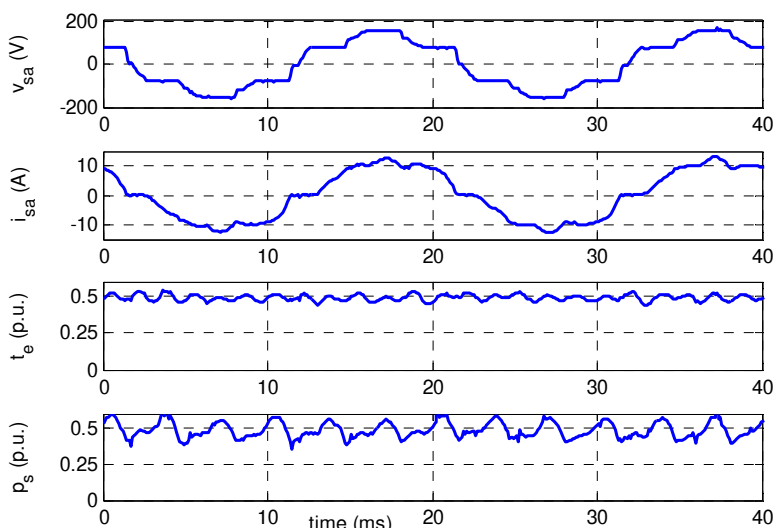

Fig. 20. Experimental steady state waveforms of the enhanced control scheme with $T_{e}=0.5$ p.u. (resonant controllers enabled)

Figs18-20 prove that the system works properly below and around the synchronism. The operation above the synchronism has been also investigated: Fig. 21 shows the test results with $\omega_{m} \approx 1.13$ p.u. and $T_{e}{ }^{*}=0.5$ p.u.. As expected, the period of the rotor currents is about $15 \mathrm{~ms}$, the average stator frequency is 1.0 p.u. and the ripple component at $300 \mathrm{~Hz}$ in the torque is killed.

The behavior of the system during the enabling of the resonant controllers is described in Fig. 22, which refers to an experimental test. The system is operating below synchronism at $\omega_{m} \approx 0.88$ p.u and with $T_{e}=0.5$ p.u.. At $t \approx 0.1$ (s) the resonant controllers are enabled by processing their output in Fig. 5 through a variable gain which is progressively increased from 
0 to 1 in about 0.1 (s). The capability of the control in tracking the current components at $300 \mathrm{~Hz}$ improves and the torque ripple at $6 \omega_{b}(300 \mathrm{~Hz})$ decreases and disappears.

Table I compares the stator and rotor current harmonics related to the waveforms in Figs. 17 and 20: the rotor currents have been transformed on the stator frame to get the same frequency of the stator currents, in order to allow a direct comparison of the harmonic contents. The operation with resonant controllers produces less distorted stator and rotor currents with respect to the ones of the basic scheme with only PI controllers. Then, even if the aim of the control scheme was to reduce the torque ripple, they also achieve an additional benefit: namely, the reduction of the THD of the stator and rotor current. The details of the windings should be known in order to evaluate the impact of the current harmonic on the derating of the machine by superposing the eddy losses in the conductors of each harmonic. Nevertheless, Table I shows that RCs significantly decrease all the harmonic components. This leads to the conclusion that also global eddy losses decrease.
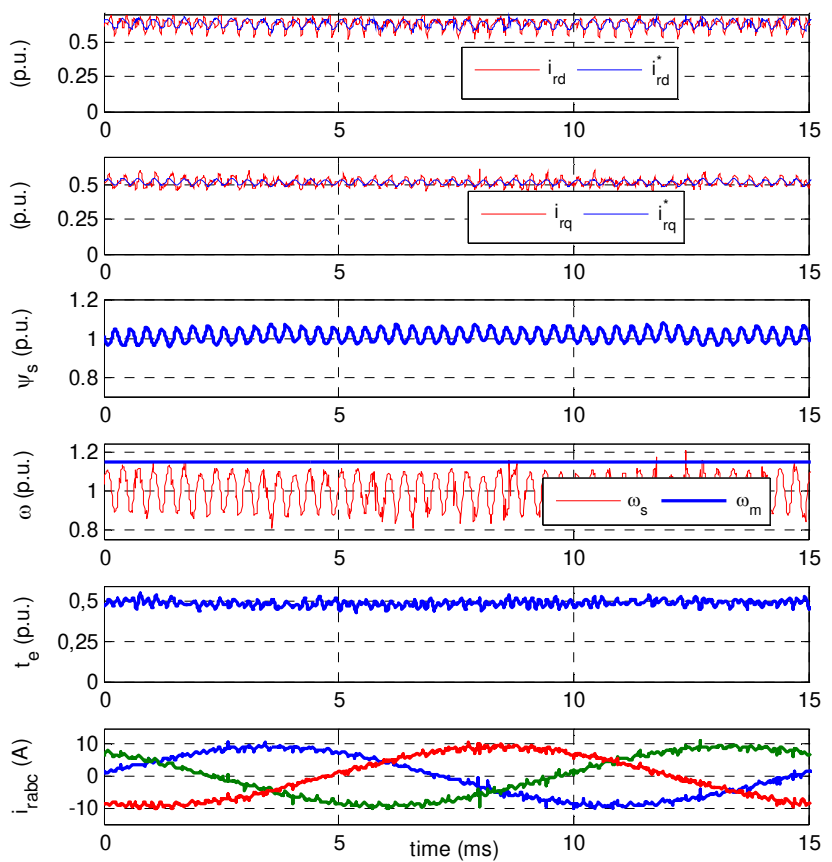

Fig. 21. Test results in the operation above synchronism $\left(\omega_{m} \approx 1.13\right.$ p.u. RC enabled).

TABLE I

HARMONIC CONTENT OF THE STATOR AND ROTOR CURRENTS FOR THE TESTS IN FIGS. 16 AND 18 FOR $T_{e}^{*}=0.5$ p.u. WITHOUT AND WITH RESONANT CONTROLLERS

\begin{tabular}{c|c|c|c|c|c|c|c|c}
\hline $\begin{array}{c}\text { current } \\
\text { controller }\end{array}$ & $h$ & 5 & 7 & 11 & 13 & 17 & 19 & THD \\
\hline \multirow{2}{*}{ PI } & $I_{s}^{(h)} / I_{s}^{(1)}$ & 0.160 & 0.077 & 0.009 & 0.027 & 0.007 & 0.008 & 0.185 \\
\cline { 2 - 8 } & $I_{r}^{(h)} / I_{r}^{(1)} \dagger$ & 0.104 & 0.037 & 0.007 & 0.024 & 0.006 & 0.008 & 0.114 \\
\hline PI-R & $I_{s}^{(h)} / I_{s}^{(1)}$ & 0.073 & 0.086 & 0.051 & 0.019 & 0.011 & 0.012 & 0.127 \\
\hline
\end{tabular}

\begin{tabular}{l|l|l|l|l|l|l|l|l}
\hline & $I_{r}^{(h)} / I_{r}^{(1)} \dagger$ & 0.020 & 0.030 & 0.035 & 0.019 & 0.008 & 0.010 & 0.055 \\
\hline
\end{tabular}

† current transformed in the stator frame, to obtain a signal at $50 \mathrm{~Hz}$
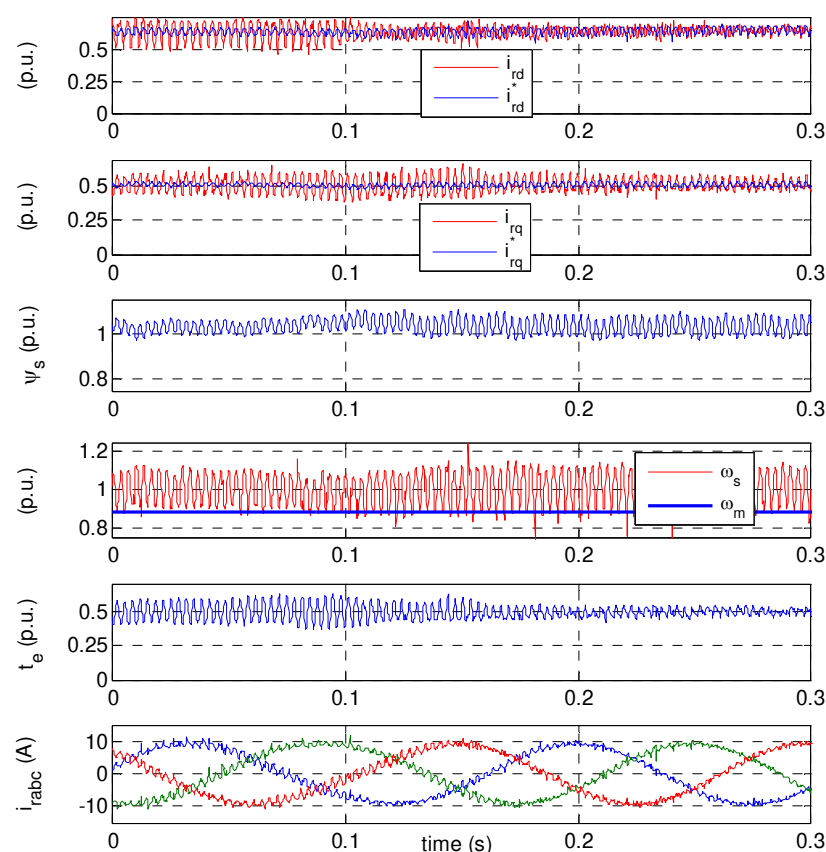

Fig. 22. Experimental behavior of the system during the enabling of resonant controllers at $t \approx 0.1$ (s).

The tracking capability of the current loops with either PI controllers or PI-RCs is compared in Fig. 23, which shows the details of the reference and actual $d$ - $q$ axis currents before and after the enabling of the resonant controllers, during the experimental tests.
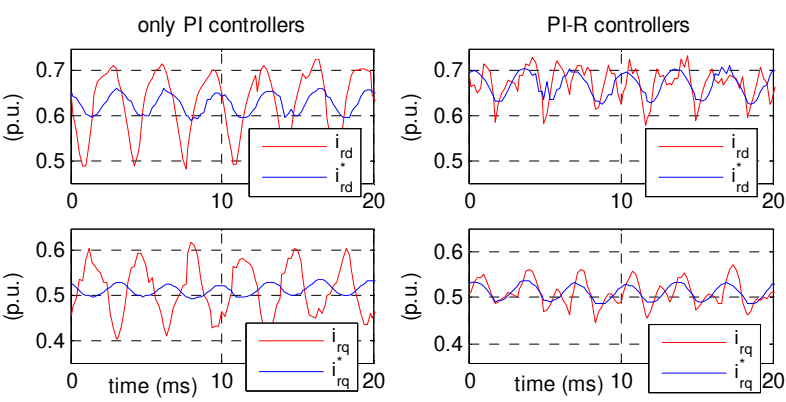

Fig. 23. Comparison (from experiments) between the ripple component of the reference and actual rotor currents without and with resonant controllers.

When only PI controllers are used (left column in Fig. 23), the ripple components at $300 \mathrm{~Hz}$ in the reference and actual $d$-axis current signals are almost in quadrature, whereas the $q$-axis components are almost in opposition: this proves the inability of PIs in controlling such a harmonic component. On the contrary, when RC are enabled (right column in Fig. 23), the reference and actual current signal component at $6 \omega_{b}(300 \mathrm{~Hz})$ are practically in phase and the main difference between the two signals is due to the component at $12 \omega_{b}(600 \mathrm{~Hz})$.

\section{CONCLUSION}

The reduction of the torque ripple in a DFIG connected to a 
constant voltage dc link by a diode bridge has been discussed in this paper. The field orientation along the stator flux linkage is considered. The $d$-axis rotor current is adjusted in such a way to annihilate the frequency error, where the actual frequency is estimated by using the symbolic derivative of the stator flux position. The $q$-axis rotor current is regulated according to the reference torque divided by the stator flux linkage amplitude, in such a way to compensate for the torque ripple. The resulting sixth harmonic in the reference rotor currents is tracked by using resonant controllers tuned at 6 times the base frequency, in addition to classical PI regulators. Simulation and experimental results show that the proposed method is able to kill the main component of the torque ripple.

\section{APPENDIX}

DFIG used in the experimental tests: (stator $\mathrm{Y}$ /rotor $\mathrm{Y}$ ) 380/185 (V), 8/12.5 (A), $3.75(\mathrm{~kW}), 50(\mathrm{~Hz}), 4$ poles, turns ratio $n_{12}=2.05, L_{m}=2.13$ (p.u.), $L_{r}=2.25$ (p.u.), $L_{s}=2.27$ (p.u.), $R_{r}=0.071$ (p.u.), $R_{S}=0.057$ (p.u.), inertia constant $H$ $=0.28$ (s). DC-bus capacitor: $2 \mathrm{mF}$. Controller parameters: $k_{p \omega}=0.31$ p.u., $k_{i \omega}=7.98 \mathrm{~s}^{-1}, k_{p I}=1.58$ p.u., $k_{i I}=109.3 \mathrm{~s}^{-1}, K_{r}$ $=30$ p.u., $\omega_{c}=7 \mathrm{rad} / \mathrm{s}$.

\section{REFERENCES}

[1] H. Kakigano, Y. Miura, T. Ise ,"Low-voltage bipolar-type dc microgrid for super high quality distribution,” IEEE Trans. Pow. Electron., vol. 25, no. 12, pp. 3066-3075, Dec. 2010.

[2] P. Karlsson and J. Svensson, "dc bus voltage control for a distributed power system”, IEEE Trans. Pow. Electron., vol. 18, no 6, pp.1405 1412, 2003.

[3] Lie Xu, Dong Chen, "Control and operation of a dc microgrid with variable generation and energy storage, "IEEE Trans. Power. Del., vol. 26, no. 4, pp. 2513-2522, Oct. 2011.

[4] F. Blaabjerg, Z. Chen and S. B. Kjaer, "Power electronics as efficient interface in dispersed power generation system”, IEEE Trans. Power Electron., vol. 19, no. 5, pp.1184 -1194, 2004.

[5] T. Ahmed, K. Nishide, M. Nakaoka, "Advanced control of PWM converter with variable-speed induction generator," IEEE Trans. Ind. Appl., vol. 42, no. 4, pp. 934-945, Jul.-Aug. 2006.

[6] Md. Enamul Haque, M. Negnevitsky, K. M. Muttaqi, “A novel control strategy for a variable-speed wind turbine with a permanent-magnet synchronous generator,” IEEE Trans. Ind. Appl., vol. 46, no. 1, Jan. 2010, pp. 331-339.

[7] C. Xia, Q. Geng, X. Gu, T. Sgi, Z. Song, "Input-output feedback linearization and speed control of a surface permanent-magne synchronous wind generator with the boost-chopper converter," IEEE Trans. Ind. Electron., vol. 59, no. 9, Sept. 12 pp. 3489-3500.

[8] M. F. Iacchetti, G. D. Marques, R. Perini, "A Scheme for the Power Control in a DFIG Connected to a DC-Bus via a Diode Rectifier,” IEEE Trans. Pow. Electron., Early access articles, 2014 DOI:10.1109/TPEL.2014.2317947.

[9] G. D. Marques, M. F. Iacchetti, "Stator Frequency Regulation in a Field Oriented Controlled DFIG Connected to a DC Link," IEEE Transactions on Industrial Electronics, vol. 61, no. 11, pp. 5930-5939, Nov. 2014.

[10] R. Cárdenas, R. Peña, S. Alepuz, G. Asher, "Overview of control systems for the operation of DFIGs in wind energy applications,” IEEE Trans. Ind. Electron., vol. 60, n 7, pp. 2776-2798, July 2013.

[11] R. Pena, J. C. Clare, and G. M. Asher, "Doubly fed induction generator using back-to-back PWM converters and its application to variablespeed wind-energy generation,” Proc. Inst. Elect. Eng. -Elect. Power Appl., vol. 143, pp. 231-241, May 1996.

[12] R. Pena, J. C. Clare, and G. M. Asher, "A doubly fed induction generator using back-to-back PWM converters supplying an isolated load from a variable speed wind turbine," Proc. Inst. Elect. Eng.-Elect. Power Appl., vol. 143, no. 5, pp. 380-387, Sep. 1996.

[13] I. Jadric, D. Borojevic, M. Jadric, "Modeling and control of synchronous generator with an active dc load, "IEEE Trans. Power Electron., vol. 15, no. 2, pp. 303-311, Mar. 2000.
[14] Feifei Bu, Yuwen Hu, Wenxin Huang, Shenglun Zhuang, Kai Shi, "Wide-speed-range-operation dual stator-winding induction generating system for wind power applications," IEEE Trans. on Pow. Electron., early access articles, 2014, DOI:10.1109/TPEL.2014.2308222.

[15] A. C. Smith, R. Todd, M. Barnes, P. J. Tavner, "Improved energy conversion for doubly fed wind generators," IEEE Trans. Ind. Appl., vol. 42, no. 6, Nov. - Dec. 2006 pp. 1421 - 1428.

[16] N. Holtsmark, H. J. Bahirat, M. Molinas, B. A. Mork, H. K. Hoidalen, "An All-dc Offshore Wind Farm With Series-Connected Turbines: An Alternative to the Classical Parallel AC Model?” IEEE Trans. Ind. Electron., vol. 60, no. 6, pp. 2420-2428, June 2013.

[17] A. Di Gerlando, G. M. Foglia, M. F. Iacchetti, R. Perini, "Comprehensive Steady State Analytical Model of a Three Phase Diode Rectifier Connected to a Constant DC Voltage Source,” IET Power Electronics, vol. 6, no 9, pp. 1927-1938, Nov. 2013.

[18] A. Kumar Jain, V.T. Ranganathan, "Wound Rotor Induction Generator with Sensorless Control and Integrate Active Filter for Feeding Nonlinear Loads in a Stand-Alone Grid,” IEEE Trans. on Ind. Electron., vol. 55, No.1pp. 218 - 228, Jan. 2008.

[19] D. Forchetti, G. Garcia, M. I. Valla, “Adaptive Observer for Sensorless Control of Stand-Alone Doubly Fed Induction Generator,” IEEE Trans. on Ind. Electronics, Vol. 56, N 10, pp. 4174 - 4180, Oct. 2009.

[20] G. Iwansky and W. Koczara, "DFIG-based power generation system with UPS function for variable-speed applications," IEEE Trans. Ind. Electron., vol. 55, no. 8, pp. 3047-3054, Aug. 2008.

[21] L. Fan, S. Yuvarajan, and R. Kavasseri, "Harmonics analysis of a DFIG for a wind energy conversion system," IEEE Trans. Energy Convers., vol. 25, no. 1, pp. 181-190, Mar. 2010.

[22] J. Hu, H. Nian, H. Xu, and Y. He, "Dynamic modeling and improved control of DFIG under distorted grid voltage conditions," IEEE Trans.Energy Convers., vol. 26, no. 1, pp. 163-175, Mar. 2011.

[23] N. Yu, H. Nian, Y. Quan, "Novel dc grid connected DFIG system with active power filter based on predictive current control," Electrical Machines and Systems Int. Conf. ICEMS 2011, 22-23 Aug 2011.

[24] H. Xu, J. Hu, and Y. He, "Operation of wind-turbine-driven DFIG systems under distorted grid voltage conditions: Analysis and experimental validations,” IEEE Trans. Power Electron., vol. 27, no. 5, pp. 2354-2366,May 2012.

[25] Changjin Liu, F. Blaabjerg, Wenjie Chen, Dehong Xu, "Stator current harmonic control with resonant controller for doubly fed induction generator,” IEEE Trans. Power Electron, vol. 27, no. 7, pp. 3207-3220, July 2012.

[26] Van-Tung Phan, Hong-Hee Lee, "Control strategy for harmonic elimination in stand-alone DFIG applications with nonlinear loads," IEEE Trans. Pow. Electron, vol. 26, no. 9, Sept. 2011, pp. 2662-2675.

[27] Heng Nian, Yipeng song, "Direct power control of doubly fed induction generator under distorted grid voltage," IEEE Trans. on Pow. Electron., vol. 29, No. 2, Feb. 2014, pp. 894-905.

[28] M.F. Iacchetti, G.D. Marques, "Enhanched torque control in a DFIG connected to a DC grid by a diode rectifier," accepted for presentation to $16^{\text {th }}$ Conference on Power electronics and Applications EPE'14-ECCE, 26-28 August 2014, Lappeenranta, Finland.

[29] S. Shen, B. Mwinyiwiwa, Y. Zhang, B.T. Ooi, "Sensorless Maximum Power Point Tracking of Wind by DFIG Using Rotor Position Phase Lock Loop (PLL)," IEEE Trans. Power Electron., vol. 24, No.4, pp. 942-951, Apr. 2009.

[30] R. Cárdenas, R. Pena, J. Clare, G. Asher, J. Proboste "MRAS Observers for sensorless control of Doubly-Fed Induction Generators," IEEE Trans. Power Electron., vol. 23, No.3, pp. 1075 - 1084, May 2008.

[31] F. Castelli-Dezza, G. Foglia, M. F. Iacchetti, and R. Perini, “An MRAS observer for sensorless DFIM drives with direct estimation of the torque and flux rotor current components," IEEE Trans. Power Electron.,vol. 27, no. 5, pp. 2576-2584, May 2012.

[32] G. D. Marques, D. M. Sousa, "Air-gap power vector based sensorless method for DFIG control without flux estimator”, IEEE Trans. Ind. Electron., vol. 58, no. 10, pp. 4717-4726, Oct. 2011.

[33] R. Cárdenas, R. Pena, J. Proboste, G. Asher, J. Clare "MRAS Observer for Sensorless Control of Standalone Doubly Fed Induction Generators," IEEE Trans. on En. Conv., vol. 20, No. 4, Dec. 2005 pp. 710 - 717.

[34] P. Naslin, "Introduction à la commande optimale," Dunod, Paris, 1965, pp. 23-30.

[35] G. D. Marques, D. M. Sousa, "Understanding the DFIG during Voltage Dips,” IEEE Trans. En. Conv., vol. 27, no. 2, June 2012, pp. 421-431. 
